\title{
The Practice of Problem-Based Learning: A Guide to Implementing PBL in the College Classroom
}

\author{
Sandra C. Williamson* \\ College of Education, Wilmington University, New Castle, DE, USA \\ *Corresponding author: Sandra.C.Williamson@wilmu.ed
}

Received March 01, 2014; Revised March 05, 2014; Accepted March 10, 2014

\begin{abstract}
The Practice of Problem-based Learning: Implementing PBL in the College Classroom is written by professors from three disciplines: humanities, (Libby Miles); social science (C. B. Peters); and life sciences (José A. Amador). The book is a guide for the development and implementation of PBL in courses at the college level. Written in story-like narratives the cross-disciplinary approach makes this a useful book for a variety of professors from multiple disciplines.
\end{abstract}

Keywords: PBL, pedagogy, multi-disciplinary, college teaching, collaboration

Cite This Article: Sandra C. Williamson, "The Practice of Problem-Based Learning: A Guide to Implementing PBL in the College Classroom.” American Journal of Educational Research, vol. 2, no. 3 (2014): 152-153. doi: 10.12691/education-2-3-7.

From the beginning of the book, The Practice of Problem-based Learning, instantly engages the reader with its story-like narratives. Professors from three disciplines, humanities (Libby Miles); social science (C. B. Peters); and life sciences (José A. Amador) collaborate to write this practical guide for implementing problem-based learning. The cross-disciplinary approach makes this a useful book for a variety of instructors from multiple disciplines teaching college-level courses.

There are five chapters: chapter 1, Why (We) Use PBL; chapter 2, Changing the Landscape; chapter 3, No Problems? No Problems, chapter 4, Controlling Chaos in PBL: The Messy Middle, and chapter 5, What Now? Evalution, Revision, and Reflection. The authors use stories and conversations throughout the book to describe the differences and similarities among their pedagogies and the challenges each of them have encountered on their journeys to implement Problem-based Learning (PBL) in their courses. Personal reflections provide the basis for discussions centered on topics such as course design, group work, and assessment.

The first chapter captures the reader's attention when the authors delve into scenarios that describe the first day of class. Drawn into the collaborative dialogues that describe a different type of teaching paradigm, the chapter offers information about What is PBL?, A Brief History, and What Isn't PBL.

Chapter 2, Changing the Landscape, focuses on the context and culture of the classroom. Through their personal experiences, the authors recount the transformations that occurrred in their classrooms. Clearly a major change in the instructor's role and student involvement are two issues that infuence the success of PBL. Three key elements recommended for considerations when redesigning the course and learning enviornment are the extent and duration of using PBL, the establishment of stable groups for collaboration, and the methods of assessment and evaluation.

The authors propose that the most challenging aspect of designing PBL instruction is writing the problem. In chapter 3, No Problems? No Problem, the authors share their successes and failures writing scenarios for problembased activities. Using critiqued problems, the authors explain why specific elements are successful and which features are inadequate from particular instructional goals, different disciplines and diverse student developmental levels. Further information about writing a problem focuses on three specific features they believe are important: the content and concepts, the story, and the structure. At the end of the chapter, the authors present scenarios of problems they have used in their courses.

Pedagogical approaches are addressed in the fourth chapter, which the authors refer to as the "messy middle." There are two important sections: instructional perspectives for faculty and for students. From the faculty perspective, they provide suggestions on sequencing, pacing, preparing a syllabus, asking the right questions, and keeping students on tasks. The students' point of view includes information about preparation, workflow, reporting, and goals. Throughout the chapter, the authors use their personal experiences to discuss these issues.

The final chapter focuses on a discussion of evaluation, revision, and reflection while highlighting the positive aspects of PBL. Each author provides a summary on the way he or she approaches evaluation. Their reflections reveal differences that exist because of personal style and choice, content, size of classes, and focus of the course. The common theme among all three approaches is the collaborative nature of problem-based learning while evaluating the learning and contributions of individual students. [[1], p.101] Topics such as peer evaluation, accountabiity, writing projects, exams, and presentations 
give the reader a broad overview of various evaluation methods. Finally, the chapter discusses what worked and what did not work in the context of revision and reflecting on practice.

Threaded throughout the narratives are authors' illustations of why PBL works in their classrooms. They also provide a must-read for individuals seeking a refresher book about problem-based learning. Whether you are a novice seeking to implement PBL soon, or a seasoned veteran of PBL seeking new ideas, this book is interesting reading in a storytelling format.

\section{References}

[1] Amador, J.A., Miles, L., \& Peters, (2007). The practice of problem-based learning: A guide to implementing PBL in the college classroom. Boston: Anker. 140 pp. 